\title{
Vitamin D deficiency is associated with mortality in the medical intensive care unit
}

\author{
Sindhaghatta Venkatram¹, Sridhar Chilimuri ${ }^{2}$, Muhammad Adrish', Abayomi Salako², Madanmohan Patel ${ }^{2}$ and \\ Gilda Diaz-Fuentes ${ }^{1 *}$
}

\begin{abstract}
Introduction: The incidence of vitamin D deficiency in critically ill patients has been reported to range from as low as $17 \%$ to as high as $79 \%$. Data regarding the relationship between 25 -hydroxyvitamin D levels and outcomes in the medical intensive care unit are sparse. The goal of the study was to evaluate the prevalence of 25hydroxyvitamin D deficiency in the medical intensive care unit and its relationship with outcomes.

Method: This was a retrospective study in a medical intensive care unit (MICU) at an inner city community hospital. The study period was between October 2009 and February 2010.

Results: Of the 932 patients admitted during the study period, 25-hydroxyvitamin D vitamin D (25(OH)D) levels were available in 523 (53\%); 86 of them were excluded from the study due to readmission to the intensive care unit. Deficiency was defined as 0 to $19.9 \mathrm{ng} / \mathrm{dL} 25(\mathrm{OH}) \mathrm{D}$ levels, insufficiency as 20 to $29.9 \mathrm{ng} / \mathrm{dL}$, and normal levels as $\geq 30 \mathrm{ng} / \mathrm{dL}$. Of the 437 patients studied, 25(OH)D deficiency was identified in 340 (77.8\%), insufficiency in 74 (16.9\%), and normal levels in $23(5.3 \%)$ patients. Patients with 25(OH)D deficiency/insufficiency were younger $(P=$ 0.015), were male $(P=0.001)$, and had kidney disease $(P=0.017)$ and lower total serum calcium levels $(P=0.003)$. Hospital mortality was higher in patients with $25(\mathrm{OH}) \mathrm{D}$ deficiency $(P=0.01)$. No differences in ventilator days or length of stay in the MICU were evident among the three groups. Analysis by multiple logistic regression demonstrated that acute physiology and chronic health evaluation (APACHE) IV score ((odds ratio (OR) 1.036; 95\% confidence interval $(\mathrm{Cl}) 1.024-1.048, P<0.0001)$, ventilator requirement $(\mathrm{OR} 7.7 ; 95 \% \mathrm{Cl} 4.3-13.98, \mathrm{P}<0.0001), 25$ $(\mathrm{OH}) \mathrm{D}$ levels(OR 0.942; 95\% Cl 0.942-0.904, $P<0.0005)$ and 25(OH) D deficiency (OR 8.7; 95\% Cl 1.03-72.8, $P<$ $0.0469)$ showed statistical significance. There was no association between $25(\mathrm{OH})] \mathrm{D}$ insufficiency and hospital mortality. The mean $25(\mathrm{OH}) \mathrm{D}$ level of survivors $(27.9 \pm 9.7 \mathrm{ng} / \mathrm{dL})$ was higher than for non-survivors $(9.7 \pm 4.7 \mathrm{ng} /$ $\mathrm{dL} ; P<0.0001)$.

Conclusions: The study results demonstrate an association between $25(\mathrm{OH}) \mathrm{D}$ deficiency and hospital mortality in MICU patients. A randomized prospective study to evaluate the effect of vitamin D replacement therapy on mortality is warranted.
\end{abstract}

\section{Introduction}

Vitamin D is a fat-soluble vitamin that regulates calcium metabolism. Adequate levels of $25(\mathrm{OH}) \mathrm{D}$, the storage form of vitamin $D$, are dependent on cutaneous synthesis stimulated by ultraviolet radiation and/or adequate dietary intake of fortified foods and nutritional supplements. A deficiency in $25(\mathrm{OH}) \mathrm{D}$ is estimated to exist in

\footnotetext{
* Correspondence: gfuentes@bronxleb.org

'Albert Einstein College of Medicine, Division of Pulmonary and Critical Care Medicine, Bronx Lebanon Hospital Center, 1650 Grand Concourse, Bronx, NY, 10457, USA

Full list of author information is available at the end of the article
}

$50 \%$ to $60 \%$ of the older population in North America and worldwide [1]. Recent evidence suggests that the role of vitamin $\mathrm{D}$ is broader than the regulation of calcium metabolism. Vitamin D has been shown to have anti-inflammatory and anti-proliferative properties, and its deficiency has been linked to all-cause mortality and cardiovascular disease and cancer [2-5]. The incidence of $25(\mathrm{OH}) \mathrm{D}$ deficiency in critically ill patients has been reported to range from as low as $17 \%$ to $79 \%$ [6-8]. Data regarding the relationship between $25(\mathrm{OH}) \mathrm{D}$ levels and outcome in the medical intensive care unit (MICU) are sparse with new reports suggesting the relationship of
C Biomed Central

(c) 2011 Venkatram et al.; licensee BioMed Central Ltd. This is an open access article distributed under the terms of the Creative Commons Attribution License http://creativecommons.org/licenses/by/2.0, which permits unrestricted use, distribution, and reproduction in any medium, provided the original work is properly cited. 
deficiency in $25(\mathrm{OH}) \mathrm{D}$ and an increase in mortality in the critically ill [6-9].

Most experts agree that levels less than $20 \mathrm{ng} / \mathrm{dL} 25$ $(\mathrm{OH}) \mathrm{D}$ are considered deficient and levels between 20 to $30 \mathrm{ng} / \mathrm{dL}$ are insufficient [10-12].

The goal of the study was to evaluate the prevalence of $25(\mathrm{OH}) \mathrm{D}$ deficiency in an inner-city MICU. The primary outcome was hospital mortality, and secondary outcomes included duration of mechanical ventilation and MICU length of stay. A subgroup analysis for primary and secondary outcomes was performed for patients admitted from skilled nursing facilities.

\section{Materials and methods}

\section{Study design and setting}

This was a retrospective study of all patients admitted to the MICU between October 2009 and February 2010 at a 26-bed closed unit. Our MICU is a university-affiliated inner-city hospital staffed daily by two pulmonary and critical care-trained attending physicians, a pulmonary fellow, and internal medicine residents.

\section{Methods}

All patients admitted to the MICU who had levels of 25 $(\mathrm{OH}) \mathrm{D}$ available were included in the study. Patients readmitted to MICU during the same period of hospitalization were excluded, those patients either already had 25(OH)D levels available from the first MICU admission and repeated levels were not performed within 24 hours of MICU readmission or did not any level available. The data were collected as part of a performance improvement project looking to the prevalence of $25(\mathrm{OH}) \mathrm{D}$ deficiency in our MICU. 25(OH)D levels were collected randomly during the first 24 hours of admission to the intensive care unit. There were no strict criteria to obtain 25(OH)D levels. The physicians received education regarding the high prevalence of hypovitaminosis in our community and were encouraged to evaluate for hypovitaminosis when patients were admitted to the hospital. Baseline demographics (age, gender, and race), history of end stage renal disease (ESRD) or chronic kidney disease (CKD), as well as acute physiology and chronic health evaluation (APACHE) IV were collected. The APACHE derived risk of death during hospitalization was determined from the worst values obtained within 24 hours of MICU admission. Clinical and laboratory variables obtained during the first 24 hours of hospital admission included serum levels of total calcium, phosphate, creatinine, glucose, albumin and 25 $(\mathrm{OH}) \mathrm{D}$. Utilization and duration of invasive mechanical ventilation, ICU length of stay (LOS), and hospital mortality were analyzed. Length of stay in the MICU was defined as the time from ICU admission to time of transfer out of the MICU. This study was approved by the hospital institutional research review board, and the need for informed consent was waived.

Serum 25(OH)D concentrations were assayed by liquid chromatography-tandem mass spectrometry at Quest Diagnostics, New York, NY. The analytical sensitivity is $4 \mathrm{ng} / \mathrm{mL}$ for $25 \mathrm{OHD}_{2}$ and $25 \mathrm{OHD}_{3}$ with a reportable range of 4 to $512 \mathrm{ng} / \mathrm{mL}$ for $25 \mathrm{OHD}_{2}$ and $25 \mathrm{OHD}_{3}$

\section{Definition of Vitamin D deficiency}

There is no firm consensus regarding optimal levels of $25(\mathrm{OH}) \mathrm{D}$. According to the workshop consensus conference for vitamin D nutritional guidelines and a study that investigated the potential beneficial effects of vitamin $\mathrm{D}$ for multiple health outcomes, the minimum desirable serum level of $25(\mathrm{OH}) \mathrm{D}$ is suggested to be 20 to $30 \mathrm{ng} / \mathrm{dL}[1,10,12]$. Studies examining $25(\mathrm{OH}) \mathrm{D}$ deficiency in intensive care units have no agreement on the cutoff levels for critically ill patients, with deficiency being defined as $25(\mathrm{OH}) \mathrm{D}$ levels of less than $15 \mathrm{ng} / \mathrm{dL}$ to less than $29 \mathrm{ng} / \mathrm{dL}[8,9,13]$. In our study, we used a 25(OH)D cutoff level of less than $19.9 \mathrm{ng} / \mathrm{dL}$ to define 25(OH)D deficiency. 25(OH)D insufficiency was defined as 20 to $29.9 \mathrm{ng} / \mathrm{dL}[11,14,15]$.

\section{Definition of renal failure}

There is no consensus on the amount of dysfunction that defines acute kidney injury, with more than 30 definitions in use today [16]. Acute renal failure was defined as a serum creatinine $x>1.5$ and acute or chronic renal failure as a worsening of renal function in a patient with chronic kidney disease (serum creatinine $\times 3$ ). End-stage renal disease (ESRD) was defined as any patient with chronic kidney disease on long term hemodialysis [17].

\section{Statistical analysis}

Data analysis was conducted using the SPSS v15.0. Discrete variables are expressed as counts (percentage) and continuous variables as means \pm standard deviations (SD). For the demographic and clinical characteristics of the patients, differences between groups were assessed using the chi-squared test and Fisher's exact test for categorical variables and the Student's t-test or MannWhitney $U$ test for continuous variables. A one-way analysis of variance (ANOVA) was performed to explore the impact of admitting diagnosis which were classified in nine different categories: (a) Cardiac, (b) Gastrointestinal, (c) Metabolic, (d) Neurologic, (e) Obstructive Airway Disease, (f) others, (g) Pulmonary, (h) Renal, and (i) Sepsis, on the continuous dependent variable outcome of log-Vitamin D levels. A multiple logistic regression model was performed for the whole population, with mortality as the dependent variable, and age, gender, APACHE IV score, ventilator requirement, acute/acute 
on chronic kidney disease, ESRD, serum levels of total calcium, phosphate, creatinine, and 25(OH)D deficiency and insufficiency as independent variables. Additionally, logistic regression with a dependent variable of mortality was performed with a total of 10 independent continuous variables; (a) APACHE, (b) age, (c) 25(OH)D levels, (d) ventilator days, (e) ICU length of stay, (f) total calcium, (g) phosphate, (h) serum creatinine, (i) serum albumin, and (j) serum glucose. A $P$ value less than 0.05 was considered statistically significant. To evaluate the prognostic utility of $25(\mathrm{OH}) \mathrm{D}$ levels, a receiver-operating characteristic (ROC) curve was constructed.

\section{Results}

A total of 932 patients were admitted to the MICU during the 4-month study period. 25(OH)D levels were available for $523(56 \%)$ patients; of these, 86 patients were excluded due to readmission to the MICU during the same hospitalization. Of the 437 patients studied, $25(\mathrm{OH}) \mathrm{D}$ deficiency was identified in $340(77.8 \%)$ patients, insufficiency in $74(16.9 \%)$ patients, and normal levels in $23(5.3 \%)$ patients (Figure 1). Characteristics of the patients were stratified according to 25 $(\mathrm{OH}) \mathrm{D}$ levels on admission (Table 1). Patients with 25
$(\mathrm{OH}) \mathrm{D}$ deficiency/insufficiency were more likely to be younger $(P=0.015)$, to be male $(P=0.001)$, to have acute/acute on CKD $(P=0.017)$, and to have lower total serum calcium levels $(P=0.003)$. A comparison among the three $25(\mathrm{OH}) \mathrm{D}$ groups by admission diagnosis is shown in Table 2. There were no differences in the mean log-25(OH)D levels among the nine categories for admitting diagnosis. $(P=.099)$. Comparison of 25-hydroxyvitamin D levels among different admission diagnosis groups did not show statistical significance (Table 3).

Comparisons of primary and secondary outcomes are shown in Table 4.

\section{Primary Outcome}

Hospital mortality was higher in patients with $25(\mathrm{OH}) \mathrm{D}$ deficiency $(P=0.01)$. Comparisons of observed versus APACHE IV-predicted mortality revealed that the observed mortality was higher than the predicted mortality among patients with 25(OH)D deficiency $(24.1 \%$ versus $8.6 \%$ ) and $25(\mathrm{OH}) \mathrm{D}$ insufficiency $(12.2 \%$ versus $7 \%)$. However, in patients with normal levels of $25(\mathrm{OH})$ $\mathrm{D}$, the observed mortality was lower than predicted (4.4\% versus $8 \%)$.

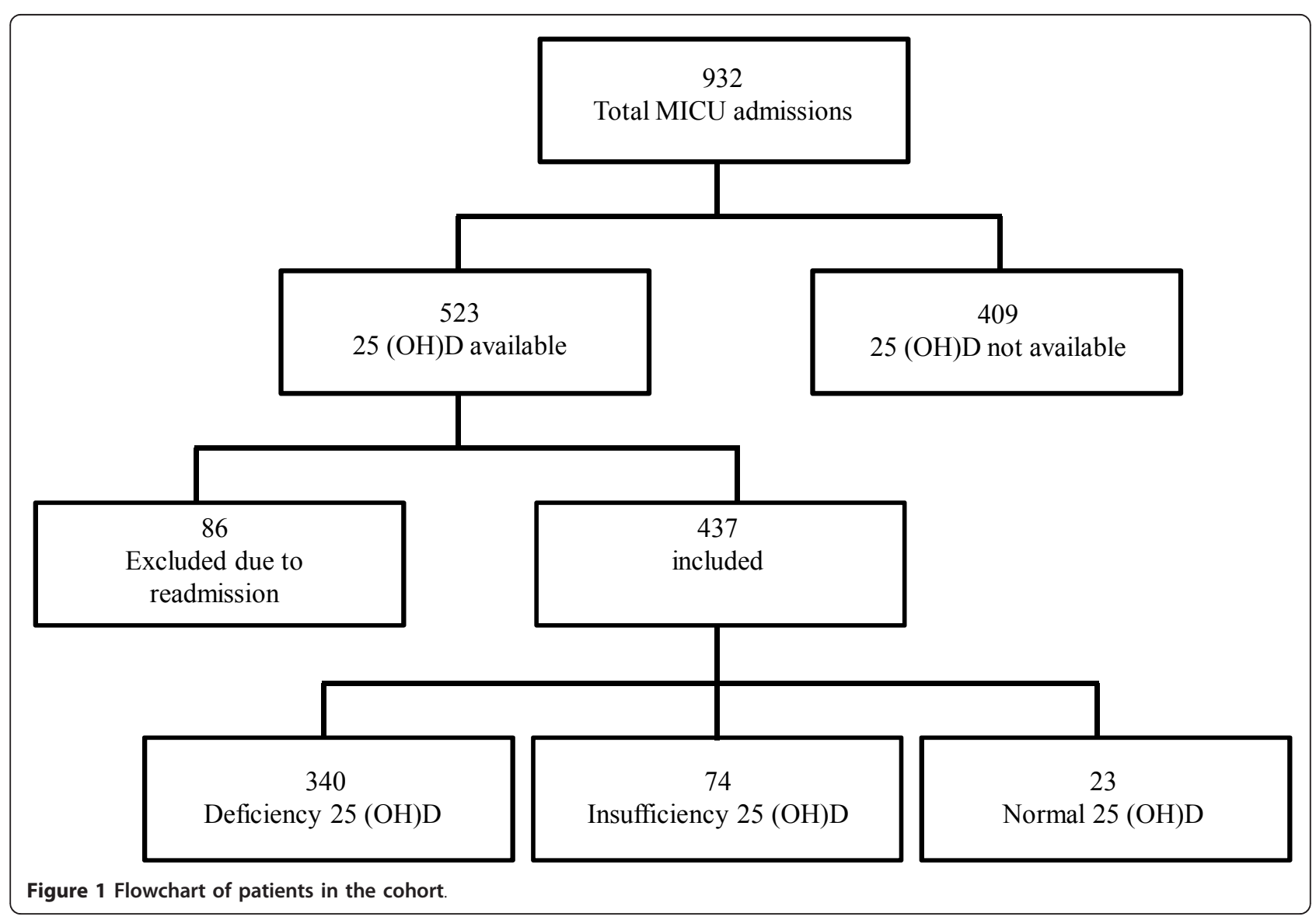


Table 1 Clinical characteristics of patients with available 25-hydroxyvitamin D levels

\begin{tabular}{|c|c|c|c|c|}
\hline Variable & $\begin{array}{c}25(\mathrm{OH}) \mathrm{D} \text { Deficiency } \\
\leq 19.9 \mathrm{ng} / \mathrm{dL} \\
\mathrm{N}=340\end{array}$ & $\begin{array}{c}25(\mathrm{OH}) \mathrm{D} \text { Insufficiency } \\
20-29.9 \mathrm{ng} / \mathrm{dL} \\
\mathrm{N}=74\end{array}$ & $\begin{array}{c}25(\mathrm{OH}) \mathrm{D} \text { Normal } \\
\geq 30 \mathrm{ng} / \mathrm{dL} \\
\mathrm{N}=23\end{array}$ & $P$ \\
\hline Age (years) & $55.6 \pm 16.5$ & $58.6 \pm 19.2$ & $65.4 \pm 16.6$ & 0.015 \\
\hline Gender - Male (\%) & $176(51.8 \%)$ & $28(37.9 \%)$ & $4(17.4 \%)$ & 0.001 \\
\hline APACHE IV & $68.3 \pm 28.1$ & $60.9 \pm 25.9$ & $67.2 \pm 20.9$ & 0.11 \\
\hline Ventilator requirement & $123(36.2 \%)$ & $23(31 \%)$ & 7 (30.4\%) & 0.63 \\
\hline Acute/acute on chronic renal failure & $92(27 \%)$ & $11(14.9 \%)$ & $2(8.7 \%)$ & 0.017 \\
\hline ESRD on hemodialysis & $21(7.1 \%)$ & $6(8.1 \%)$ & $2(8.7 \%)$ & 0.92 \\
\hline Total calcium serum (mg/dL) & $8.6 \pm 1.1$ & $9.0 \pm 1.1$ & $9.4 \pm 1.3$ & 0.0003 \\
\hline Phosphate serum (mg/dL) & $3.7 \pm 1.7$ & $4.1 \pm 5.7$ & $3.3 \pm 1.2$ & 0.34 \\
\hline
\end{tabular}

APACHE IV, acute physiology and chronic health evaluation; ESRD, end-stage renal disease; N, Number; 25(OH)D, 25-hydroxyvitamin D

Early ( $\leq 2$ days) versus late mortality is shown in Table 5 . Classification percentages were similar between the mortality and $25(\mathrm{OH}) \mathrm{D}$ groups, but a higher percentage of cases with insufficient $25(\mathrm{OH}) \mathrm{D}$ experienced early mortality (13.8\%) than late mortality (7.9\%). A higher percentage of cases with deficient $25(\mathrm{OH}) \mathrm{D}$ levels were classified as late mortality $(69.5 \%)$ versus early mortality $(30.5 \%)(\mathrm{P}<0.0005)$

Unadjusted and adjusted odds ratios (ORs) for mortality are shown in Table 6 . The following variables demonstrated statistical significance after adjustment by multiple logistic regression analysis: APACHE IV score (OR 1.036; 95\% confidence interval (CI) 1.024-1.048, $P<$ 0.0001 ), ventilator requirement (OR 7.7; 95\% CI 4.313.98, $P<0.0001)$, and $25(\mathrm{OH}) \mathrm{D}$ deficiency (OR 8.7; 95\% CI 1.03-72.8, $P<0.0469)$. No association between 25(OH)D insufficiency and hospital mortality (OR 4.3; 95\% CI 0.4-40.9, $P=0.2081$ ) was evident.

Logistic regression with a dependent variable of mortality and continuous variables was performed for greater retention of information during analysis (Table 7 ). Wald statistics indicated that four variables contributed significantly to the model: APACHE $(\chi 2=29.01$, OR 1.037; 95\% CI 1.023-1.050, $P<.0005), 25(\mathrm{OH}) \mathrm{D}$ levels $(\chi 2=8.083$, OR 0.94; 95\% CI 0.904-0.982, $P=$ $0.004)$, admission albumin levels $(\chi 2=13.27$, OR 0.457;
95\% CI 0.0.300-1.091, $P<0.0005)$, and ventilator days $(\chi 2=9.2$, OR 1.15 ; 95\% CI 1.054-1.272, $P=0.002)$.

The mean $25(\mathrm{OH}) \mathrm{D}$ level for survivors $(27.9 \pm 9.7 \mathrm{ng} /$ $\mathrm{dL})$ was higher than for non-survivors $(9.7 \pm 4.7 \mathrm{ng} / \mathrm{dL}$; $P<0.0001)$. The ROC curve for $25(\mathrm{OH}) \mathrm{D}$ levels is shown in Figure 2, and the $25(\mathrm{OH}) \mathrm{D}$ intersection curve is shown in Figure 3. The area under the curve (AUC) was 0.66 , and the cut-off value that maximizes sensitivity at $59.8 \%$ and specificity at $58 \%$ is a $25(\mathrm{OH}) \mathrm{D}$ level of $10 \mathrm{ng} / \mathrm{dL}$. Sensitivity and specificity crossed at a probability level of 0.235 for the aforementioned 25(OH)D level. With a prevalence rate of $77.8 \%$, the positive predictive value (PPV) for mortality with a $25(\mathrm{OH}) \mathrm{D}$ level less than $10 \mathrm{ng} / \mathrm{dL}$ was $83.64 \%$ and the negative predictive value (NPV) was $29.52 \%$..

\section{Secondary Outcomes}

Factors that did not significantly differ between stratified groups were latitude, ventilator days and MICU length of stay. The mean latitude for our study group was $40^{\circ}$ north (SD $0.5^{\circ}$ north). There was no difference in ventilator days or MICU LOS for the different admitting diagnosis groups.

Comparison of patients with available 25(OH)D levels versus patients without $25(\mathrm{OH}) \mathrm{D}$ revealed no difference

Table 2 Comparison of admission diagnosis groups based on deficient, insufficient, and normal 25-hydroxyvitamin D levels

\begin{tabular}{|c|c|c|c|c|}
\hline Variable & $\begin{array}{c}25(\mathrm{OH}) \mathrm{D} \text { Deficiency } \leq 0-19.9 \mathrm{ng} / \mathrm{dL} \\
\mathrm{N}(\%)=340\end{array}$ & $\begin{array}{c}\text { 25(OH)D Insufficiency 20-29.9 ng/dL } \\
\mathrm{N}(\%)=74\end{array}$ & $\begin{array}{c}25(\mathrm{OH}) \mathrm{D} \text { Normal } \geq 30 \mathrm{ng} / \mathrm{dL} \\
\mathrm{N}(\%)=23\end{array}$ & $\begin{array}{l}\text { Total } \\
\mathrm{N}(\%)\end{array}$ \\
\hline Cardiac & $14(4 \%)$ & $5(6.7 \%)$ & $2(8.6 \%)$ & $21(4.8 \%)$ \\
\hline Gastrointestinal & $39(11.4 \%)$ & $5(6.7 \%)$ & $3(13 \%)$ & $47(10.7 \%)$ \\
\hline Metabolic & $39(11.4 \%)$ & $8(10.8 \%)$ & $3(13 \%)$ & $50(11.4 \%)$ \\
\hline Neurological & $46(13.5 \%)$ & $6(8.1 \%)$ & $3(13 \%)$ & $55(12.5 \%)$ \\
\hline Obstructive airway disease & $42(12.3 \%)$ & $17(22.9 \%)$ & $1(4.3 \%)$ & $60(13.7 \%)$ \\
\hline Pulmonary & $64(18.8 \%)$ & $13(17.5 \%)$ & $3(13 \%)$ & $80(18.3 \%)$ \\
\hline Others & $34(10 \%)$ & $10(13.5 \%)$ & $4(17.3 \%)$ & $48(10.9 \%)$ \\
\hline Renal & 19(5.5\%) & $3(4 \%)$ & $0(0 \%)$ & $22(5 \%)$ \\
\hline Sepsis/Septic shock & $43(12.6 \%)$ & $7(9.4 \%)$ & $4(17.3 \%)$ & $54(12.3 \%)$ \\
\hline
\end{tabular}


Table 3 Comparison of 25-hydroxyvitamin D levels between admission diagnosis groups*

\begin{tabular}{lc}
\hline Admission Diagnosis groups & $\begin{array}{c}\text { Mean 25-hydroxyvitamin D } \\
\text { (ng/dL) } \pm \text { SD (range) }\end{array}$ \\
\hline Cardiac disorders. N (\%) & $15.1 \pm 11.1(4-43)$ \\
Gastrointestinal disorders. N (\%) & $12.5 \pm 10.1(4-50)$ \\
Metabolic disorders. N (\%) & $13.9 \pm 8.9(4-40)$ \\
Neurological disorders. N (\%) & $12.0 \pm 9.5(4-51)$ \\
Obstructive airway disease. N (\%) & $15.7 \pm 10.6(4-74)$ \\
Pulmonary disorders. N (\%) & $13.1 \pm 8.4(4-42)$ \\
Others. N (\%) & $16.6 \pm 11.7(4-73)$ \\
Renal disorders. N (\%) & $12.2 \pm 6.5(4-26)$ \\
Sepsis/Septic shock. N (\%) & $13.3 \pm 9.2(4-42)$ \\
\hline
\end{tabular}

* No statistical significance was reached between the groups

for age, gender, APACHE IV score, ventilator requirement or mortality (Figure 4).

\section{Discussion}

Our results demonstrate that $56 \%$ of patients admitted to our MICU have a $25(\mathrm{OH}) \mathrm{D}$ deficiency. This incidence is higher than other large studies showing a prevalence between $20 \%$ to $40 \%[6,8,9]$. Inner-city hospitals are unique in the sense that they care for an underserved population with a higher rate of unemployment, lower income, higher use of toxic substances and, in general, less than optimum medical care; all of which lead to an increased incidence of uncontrolled diseases and a higher risk for hypovitaminosis.

We found an association between 25(OH)D deficiency and hospital mortality in our MICU population. $25(\mathrm{OH})$ $\mathrm{D}$ levels were significantly higher in survivors than in non-survivors. In our study, total serum hypocalcemia was not associated with an increased hospital mortality, although levels of ionized calcium, 25(OH)D3 and PTH were not studied. Our data are in line with another study showing a correlation between serum levels of albumin and mortality [5]. Several explanations are possible for the association between $25(\mathrm{OH}) \mathrm{D}$ deficiency and hospital mortality. The vitamin $\mathrm{D}$ receptor is expressed in nearly all cells in the body, and the activating enzyme 1-alpha-hydroxylase is expressed in many tissue types. Laboratory, cell culture, and animal studies suggest that vitamin D may lower cancer risk by inhibiting cell proliferation, angiogenesis, metastasis, and inflammation, as well as inducing apoptosis and cellular differentiation. Several of these mechanisms are relevant to atherosclerosis and cardiovascular disease, as well as sepsis, respiratory failure, and other diseases commonly seen in the critically ill [12,18-20]. Deficiency of $25(\mathrm{OH})$ $\mathrm{D}$ has been implicated as a cause of increased cardiovascular events and death [21-24]. The increased mortality in the critically ill with vitamin $\mathrm{D}$ deficiency might be due to changes in glucose and calcium metabolism, and/ or immune and endothelial cell dysfunction due to the deficiency [25-29].

Endothelial cell dysfunction has been proposed as a potential cause of multiple organ dysfunction syndrome [30-32]. It is possible that $25(\mathrm{OH}) \mathrm{D}$ deficiency amplifies the metabolic derangements and impaired immune regulation seen in critically ill states, which may lead to worse outcomes than would be experienced with normal vitamin D levels. Furthermore, 25(OH)D deficiency has been implicated in sepsis, stroke, inflammatory bowel disease, autoimmune conditions and asthma [33-39].

Contrary to the study by McKinney et al., we did not find a correlation between $25(\mathrm{OH}) \mathrm{D}$ deficiency and an increased length of stay among patients admitted to the MICU; it is important to note that in their study the LOS was dichotomized to a LOS less and more than three days, respectively [8].

Risk factors for low vitamin D levels include older age, living in northern latitudes, sun avoidance, dark skin pigmentation, obesity, low dietary intake of vitamin $\mathrm{D}$, and various medical conditions, especially malabsorption syndromes. These factors are especially important for older patients in nursing home facilities [40].

Causes of low 25(OH)D levels in patients admitted to ICUs are multifactorial. In addition to the well-known etiologies, it is important to consider other factors such as interaction with medications, abnormal gastrointestinal function and the effect of fluid resuscitation [41].

Contrary to our expectations and reports in the literature, our study showed that patients with either $25(\mathrm{OH})$

Table 4 Comparison of outcomes based on deficient, insufficient, and normal 25-hydroxyvitamin D levels.

\begin{tabular}{|c|c|c|c|c|}
\hline Variable & $\begin{array}{c}\text { 25(OH)D Deficiency } \\
\leq 0-19.9 \mathrm{ng} / \mathrm{dL} \\
\mathrm{N}=340\end{array}$ & $\begin{array}{c}\text { 25(OH)D Insufficiency } \\
\begin{array}{c}20-29.9 \mathrm{ng} / \mathrm{dL} \\
\mathrm{N}=74\end{array}\end{array}$ & $\begin{array}{l}\text { 25(OH)D Normal } \\
\begin{array}{c}\geq 30 \mathrm{ng} / \mathrm{dL} \\
\mathrm{N}=23\end{array}\end{array}$ & $P$ \\
\hline Actual Hospital Mortality & $82(24.1 \%)$ & $9(12.2 \%)$ & $1(4.4 \%)$ & 0.01 \\
\hline Predicted ICU mortality [APACHE IV] & $8.6 \%$ & $7 \%$ & $8 \%$ & \\
\hline Days on a ventilator & $6.9 \pm 6.0$ & $5.9 \pm 6.0$ & $6.4 \pm 5.1$ & 0.77 \\
\hline ICU length of stay [days] & $4.3 \pm 4.5$ & $3.7 \pm 3.9$ & $4.2 \pm 3.7$ & 0.54 \\
\hline
\end{tabular}

APACHE IV, acute physiology and chronic health evaluation; N, number; 25(OH)D, 25-hydroxyvitamin D. 
Table 5 Contingency table of cross tabulations between classifications of Vitamin D levels and stages of mortality ( $N=92)$

\begin{tabular}{|c|c|c|c|c|}
\hline & $\begin{array}{c}\text { 25(OH)D Deficiency } \leq 0-19.9 \mathrm{ng} / \mathrm{dL} \\
\mathrm{N}=82\end{array}$ & $\begin{array}{c}25(\mathrm{OH}) \mathrm{D} \text { Insufficiency } 20-29.9 \mathrm{ng} / \mathrm{dL} \\
\mathrm{N}=9\end{array}$ & $\begin{array}{l}25(\mathrm{OH}) \mathrm{D} \text { Normal } \geq 30 \mathrm{ng} / \mathrm{dL} \\
\qquad \mathrm{N}=1\end{array}$ & Total \\
\hline Early Mortality (frequency) & 25 & 4 & 0 & 29 \\
\hline$\%$ within mortality category & 86.2 & 13.8 & 0.0 & 100.0 \\
\hline$\%$ within Vitamin D category & 30.5 & 44.4 & 0.0 & 31.5 \\
\hline$\%$ of total & 27.2 & 4.3 & 0.0 & 31.5 \\
\hline Late Mortality (frequency) & 57 & 5 & 1 & 63 \\
\hline$\%$ within mortality category & 90.5 & 7.9 & 1.6 & 100.0 \\
\hline$\%$ within Vitamin D category & 69.5 & 55.6 & 100.0 & 68.5 \\
\hline$\%$ of total & 62.0 & 5.4 & 1.1 & 68.5 \\
\hline
\end{tabular}

$\mathrm{N}$, number

D deficiency or insufficiency were generally younger than patients with normal $25(\mathrm{OH}) \mathrm{D}$ levels and they were predominantly of male gender. The association between 25(OH)D levels and hospital mortality in men and in younger patients is unclear. Most published studies show a higher prevalence of vitamin $\mathrm{D}$ deficiency in women and the elderly $[9,42,43]$. The large multicenter study done by Braun et al. confirmed our association between low 25(OH)D levels and younger age, but not with male gender [9]. These findings could be just a reflection of the general vitamin deficiency in our population.

In our cohort, 93\% of patients with ESRD and 98\% of patients with acute and acute on CKD had 25(OH)D deficiency/insufficiency, and these findings are consistent with other published findings [14,44-49]. Chronic kidney disease is characterized by decreased renal phosphate excretion, with resultant increases in serum phosphate levels; furthermore, there is decreased conversion of vitamin $\mathrm{D}$ to its active form, 1,25-dihydroxyvitamin D3 $(1,25(\mathrm{OH}) \mathrm{D} 3)$, resulting in decreased levels of circulating $1,25(\mathrm{OH}) \mathrm{D} 3$ and serum calcium and decreased intestinal calcium absorption. The hyperphosphatemia, hypocalcemia, and decreased levels of active vitamin D result in increased synthesis and secretion of parathyroid hormone. Some studies found no interaction between low levels of 25(OH)D and PTH concentrations or calcium levels. This could suggest that the association of $25(\mathrm{OH}) \mathrm{D}$ status and mortality is not significantly modified by PTH or calcium levels $[6,47,50]$. Vitamin D deficiency has been associated with cardiovascular mortality and all-cause mortality in patients with CKD [44-47,50-52]. There is no conclusive data regarding vitamin $\mathrm{D}$ supplementation and decrease in mortality or other outcomes in critically ill patients. A meta-analysis of randomized controlled trials suggested that supplementation of 400 to 830 IU of vitamin D decreased mortality in the general population during the trial periods [21]. In a subsequent study, there was no association between vitamin D classes and mortality [6]. Levels of $25(\mathrm{OH}) \mathrm{D} \geq 150 \mathrm{ng} / \mathrm{dL}$ are potentially harmful and are associated with elevated risk of hypercalcemia, vascular soft tissue calcification, and hyperphosphatemia [53]. Vitamin D intoxication can potentially be life-threatening but the majority of officially recorded cases could be related to prolonged intakes of $>40,000$ IU per day [54]. One small study looking at the short-term metabolic effect of high dose oral vitamin D3 replacement in the intensive care unit did not reveal any complications [55]. A recent Cochrane review of fifty randomized trials with 94,148 participants showed that vitamin D in the form of vitamin $D_{3}$ seems to decrease mortality in predominantly elderly women [56].

Our work has several potential limitations. First, this was a retrospective single center study and we did not sample 25(OH)D levels sequentially. The $25(\mathrm{OH}) \mathrm{D}$ levels obtained on admission are probably a reflection of pre-admission deficiency. Vitamin D levels were not

Table 6 Logistic regression analysis for mortality risk using categorical variables

\begin{tabular}{ccccc}
\hline Variable & Unadjusted OR for Death & $\boldsymbol{P}$ & Adjusted OR for Death & 95\% Cl \\
\hline Ventilator requirement & 11.7 & $<0.0001$ & 7.7 & $8.3-13.98$ \\
25(OH)D deficiency & 6.99 & 0.0289 & 8.7 & $1.03-72.8$ \\
25(OH)D insufficiency & 3.05 & 0.29 & 0.0469 & $0.4-40.9$ \\
\hline
\end{tabular}

APACHE IV, acute physiology and chronic health evaluation; $\mathrm{Cl}$, confidence interval; 25(OH)D, 25-hydroxyvitamin D; OR, odds ratio. 
Table 7 Logistic regression analysis for mortality risk using continuous variables

\begin{tabular}{lllll}
\hline Variable & Wald $\chi^{2}$ & $\boldsymbol{P}$-value & OR & $\mathbf{9 5 \%} \mathbf{C l}$ \\
\hline APACHE & 29.013 & $<.0005$ & 1.037 & $1.023-1.050$ \\
25(OH)D & 8.083 & .004 & 0.942 & $0.904-0.982$ \\
Ventilator days & 9.285 & .002 & 1.158 & $1.054-1.272$ \\
Albumin & 13.276 & $<.0005$ & 0.457 & $0.300-1.091$ \\
Age & 0.432 & .511 & 1.007 & $0.987-1.027$ \\
ICU LOS & 0.015 & .903 & 1.007 & $0.906-1.118$ \\
Total calcium & 0.082 & .775 & 0.963 & $0.745-1.245$ \\
Phosphate & 0.047 & .828 & 1.012 & $0.910-1.125$ \\
Creatinine & 0.580 & .446 & 0.946 & $0.821-1.125$ \\
Glucose & 1.778 & .182 & 0.999 & $0.997-0.696$ \\
\hline
\end{tabular}

APACHE IV, acute physiology and chronic health evaluation; $\mathrm{Cl}$, confidence interval; 25(OH)D, 25-hydroxyvitamin D; LOS, Length of stay; OR, odds ratio.

available for all patients in this cohort; however, analysis of the groups with and without available vitamin D levels reflected no gross bias. Second, the study was completed in the fall and winter months, which have been traditionally associated with lower levels of vitamin $\mathrm{D}$, and may have overestimated the deficiency of vitamin $\mathrm{D}$ in our population. Third, our study was conducted in a MICU and cannot be generalized to cardiac, surgical, or cardiothoracic units. Fourth, our study did not intend to evaluate the association of low 25(OH)D levels and inflammatory markers or incidence of infectious diseases, neither did we attempt to see the effect of 25 $(\mathrm{OH}) \mathrm{D}$ replacement on mortality. Finally, PTH and 1,25D3 levels were not available and we cannot exclude the confounding effects of these variables.

\section{Conclusions}

In conclusion, we report on a large cohort of patients with $25(\mathrm{OH}) \mathrm{D}$ deficiency and insufficiency in a MICU setting. Our study shows a clear association between 25(OH)D levels and hospital mortality in critically ill

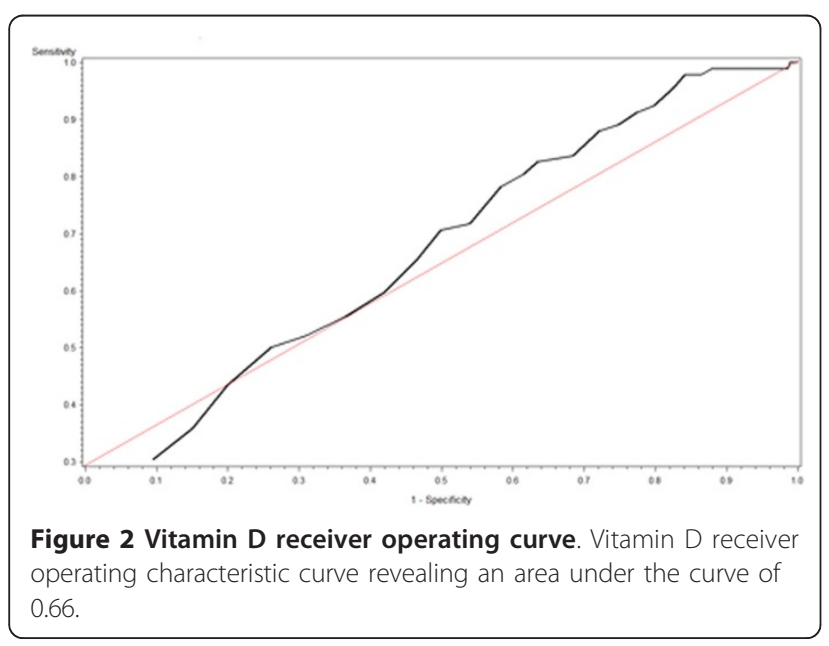

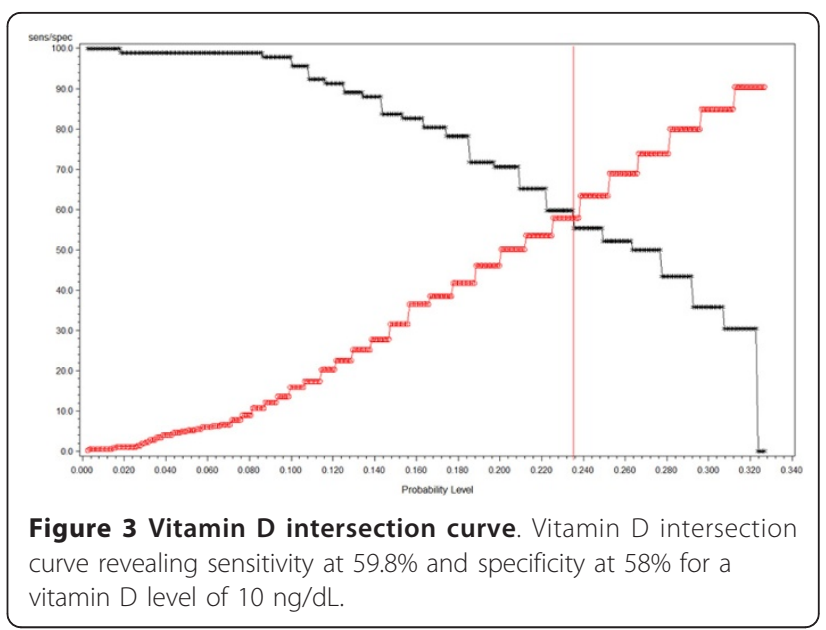

patients. 25(OH)D levels of $10 \mathrm{ng} / \mathrm{dL}$ predicted hospital mortality in $83.6 \%$ of this cohort. The observed hospital mortality for $25(\mathrm{OH}) \mathrm{D}$ deficient patients was higher than the predicted mortality based on admission APACHE IV score.

The finding that 25(OH)D deficiency, especially at levels less than $10 \mathrm{ng} / \mathrm{dL}$, is associated with increased hospital mortality has both clinical and research implications. Clinically, patients admitted to the medical ICU who present with a $25(\mathrm{OH}) \mathrm{D}$ deficiency are at greater risk for short-term hospital mortality and may therefore potentially benefit from more intensive surveillance at ICU admission. Future studies are needed to answer some of the most relevant questions such as: Is $25(\mathrm{OH})$ D deficiency merely another marker for severity of illness? Can hospital mortality, risk of infections, LOS in the intensive care unit be changed or modulated just by evaluating and correcting $25(\mathrm{OH}) \mathrm{D}$ deficiency? What are the optimal doses for replacement and what is the long term outcome in those patients? Future research is warranted to determine whether correction of $25(\mathrm{OH}) \mathrm{D}$ deficiency is associated with improved outcomes for ICU patients.

\section{Key Messages}

- 25(OH)D deficiency and insufficiency is a common finding in a medical intensive care unit.

- 25(OH)D deficiency in the intensive care unit is associated with increased risk for hospital mortality.

- There was correlation between 25(OH)D deficiency and late mortality ( $\geq 2$ days) whereas this effect was not seen in 25(OH)D insufficiency.

- A 25(OH)D level less than $10 \mathrm{ng} / \mathrm{dL}$ had a positive predictive value for hospital mortality of $83.6 \%$.

- Measurement of 25(OH)D D levels should be considered as part of the routine initial laboratory tests obtained in the medical intensive care unit. 


\title{
Comparison of patients with available 25-hydroxyvitamin D levels versus
}

\author{
patients without 25-hydroxyvitamin D levels .
}

\begin{tabular}{|l|c|c|c|}
\hline \multicolumn{1}{|c|}{ Variable } & $\begin{array}{c}25(\mathrm{OH}) \mathrm{D} \\
\text { Levels available }\end{array}$ & $\begin{array}{c}25(\mathrm{OH}) \mathrm{D} \\
\text { Levels not available }\end{array}$ & $p$ \\
\hline Age & $\mathrm{N}=437$ & $\mathrm{~N}=409$ & 0.41 \\
\hline Gender - Male (\%) & $208(47.5 \%)$ & $201(49.1 \%)$ & $95 \%$ CI $1.31-3.15$ \\
\hline APACHE IV & $67.0 \pm 27.5$ & $63.6 \pm 28.4$ & 0.67 \\
\hline Ventilator requirement & $153(35 \%)$ & $119(29 \%)$ & 0.07 \\
\hline Mortality & $92(21 \%)$ & $65(16 \%)$ & 0.07 \\
\hline
\end{tabular}

APACHE IV: acute physiology and chronic health evaluation; 25(OH)D: $25-$ hydroxyvitamin D

Figure 4 Comparison of patients with available 25 -hydroxyvitamin D levels versus patients without 25 -hydroxyvitamin $D$ levels

\section{Abbreviations}

ANOVA: one-way analysis of variance; APACHE: acute physiology and chronic health evaluation; CKD: chronic kidney disease; ESRD: end stage renal disease; ICU: intensive care unit; MICU: medical intensive care unit; $25(\mathrm{OH}) \mathrm{D}$ : 25-hydroxyvitamin D; OR: odds ratio; PTH: parathyroid hormone; ROC: receiver-operating characteristic; SD: standard deviation.

\section{Author details}

${ }^{1}$ Albert Einstein College of Medicine, Division of Pulmonary and Critical Care Medicine, Bronx Lebanon Hospital Center, 1650 Grand Concourse, Bronx, NY, 10457, USA. ${ }^{2}$ Albert Einstein College of Medicine, Department of Medicine, Bronx Lebanon Hospital Center, 1650 Grand Concourse, Bronx, NY, 10457, USA.

\section{Authors' contributions}

SV conceived the study, and participated in its design and coordination and helped to draft the manuscript, SC was involved in revising the manuscript critically for important intellectual content, MA made substantial contributions in the acquisition, analysis and interpretation of data, AS made substantial contributions in the acquisition and analysis of data, MP made substantial contributions in the acquisition of data and analysis and interpretation of data, GDF participated in the study design and coordination and helped to draft the manuscript. She gave final approval of the version to be published. All authors read and approved the final manuscript.

\section{Competing interests}

The authors declare that they have no competing interests.

Received: 26 July 2011 Revised: 20 October 2011

Accepted: 10 December 2011 Published: 10 December 2011

\section{References}

1. Norman AW, Bouillon R, Whiting SJ, Veith R, Lips P: 13th Workshop Consensus for Vitamin D Nutritional Guidelines. J Steroid Biochem Mol Biol 2007, 103:204-205.

2. Dobnig H, Pilz S, Scharnagl H, Renner W, Seelhorst U, Wellnitz B, Kinkeldei J, Boehm BO, Weihrauch G, Maerz W: Independent association of low serum 25-hydroxyvitamin D and 1,25-dihydroxyvitamin D levels with all-cause and cardiovascular mortality. Arch Intern Med 2008, 168:1340-1349.

3. Lee JH, O'Keefe JH, Bell D, Hensrud DD, Holick MF: Vitamin D deficiency: an important, common, and easily treatable cardiovascular risk factor? J Am Coll Cardiol 2008, 52:1949-1956.

4. Zittermann A, Gummert JF, Börgermann J: Vitamin D deficiency and mortality. Curr Opin Clin Nutr Metab Care 2009, 12:634-639.

5. Melamed ML, Michos ED, Post W, Astor B: 25-hydroxyvitamin D levels and the risk of mortality in the general population. Arch Intern Med 2008, 168:1629-1637.

6. Lucidarme O, Messai E, Mazzoni T, Arcade M, du Cheyron D: Incidence and risk factors of vitamin $D$ deficiency in critically ill patients: results from a prospective observational study. Intensive Care Medicine 2010, 36:1609-1611.

7. Lee P, Eisman JA, Center JR: Vitamin D deficiency in critically ill patients. N Engl J Med 2009, 360:1912-1914.

8. McKinney JD, Bailey BA, Garrett LH, Peiris P, Manning T, Peiris AN: Relationship between vitamin D status and ICU outcomes in veterans. J Am Med Dir Assoc 2011, 12:208-211.

9. Braun A, Chang D, Mahadevappa K, Gibbons FK, Liu Y, Giovannucci E, Christopher KB: Association of low serum 25-hydroxyvitamin D levels and mortality in the critically ill. Crit Care Med 2011, 39:671-677.

10. Bischoff-Ferrari HA, Giovannucci E, Willett WC, Dietrich T, Dawson-Hughes B: Estimation of optimal serum concentrations of 25-hydroxyvitamin D for multiple health outcomes. Am J Clin Nutr 2006, 84:18-28, Review. Erratum in: Am J Clin Nutr 2006, 84:1253. 
11. Malabanan A, Veronikis IE, Holick MF: Redefining vitamin D insufficiency. Lancet 1998, 351:805-806.

12. Holick MF: Vitamin D deficiency. N Engl J Med 2007, 357:266-281.

13. Lee $P$, Eisman JA, Center JR: Vitamin D deficiency in critically ill patients. N Engl J Med 2009, 360:1912-1914.

14. Thomas MK, Lloyd-Jones DM, Thadhani RI, Shaw AC, Deraska DJ, Kitch BT, Vamvakas EC, Dick IM, Prince RL, Finkelstein JS: Hypovitaminosis D in medical inpatients. N Engl J Med 1998, 338:777-783.

15. Holick MF: High prevalence of vitamin D inadequacy and implications for health. Mayo Clin Proc 2006, 81:353-373.

16. Kellum JA, Levin N, Bouman C, Lameire N: Developing a consensus classification system for acute renal failure. Curr Opin Crit Care 2002, 8:509-514.

17. Bellomo R, Ronco C, Kellum JA, Mehta RL, Palevsky P: Acute renal failuredefinition, outcome measures, animal models, fluid therapy and information technology needs: The Second International Consensus Conference of the Acute Dialysis Quality Initiative [ADQI] Group. Crit Care 2004, 8:R204-R212

18. Bouillon R, Carmeliet G, Verlinden L, van Etten E, Verstuyf A, Luderer HF, Lieben L, Mathieu C, Demay M: Vitamin D and human health: lessons from vitamin D receptor null mice. Endocr Rev 2008, 29:726-776.

19. Veldman CM, Cantorna MT, DeLuca HF: Expression of 1, 25dihydroxyvitamin D [3] receptor in the immune system. Arch Biochem Biophys 2000, 374:334-338.

20. Zittermann A: Vitamin D and disease prevention with special reference to cardiovascular disease. Prog Biophys Mol Biol 2006, 92:39-48

21. Autier P, Gandini S: Vitamin D supplementation and total mortality: a meta-analysis of randomized controlled trials. Arch Intern Med 2007, 167:1730-1737

22. Kendrick J, Targher G, Smits G, Chonchol M: 25 Hydroxyvitamin D deficiency is independently associated with cardiovascular disease in the Third National Health and Nutrition Examination Survey. Atherosclerosis 2009, 205:255-260.

23. Fiscella $K$, Franks $P$ : Vitamin $D$, race, and cardiovascular mortality: findings from a national US sample. Ann Fam Med 2010, 8:11-18

24. Giovannucci E, Liu Y, Hollis BW, Rimm EB: 25-Hydroxyvitamin D and risk of myocardial infarction in men: a prospective study. Arch Intern Med 2008, 168:1174-1180

25. Lee $\mathrm{P}$, Nair $\mathrm{P}$, Eisman JA, Center JR: Vitamin D deficiency in the intensive care unit: an invisible accomplice to morbidity and mortality? Intensive Care Med 2009, 35:2028-2032

26. van den Berghe G, Wouters P, Weekers F, Verwaest C, Bruyninckx F, Schetz M, Vlasselaers D, Ferdinande P, Lauwers P, Bouillon R: Intensive insulin therapy in critically ill patients. N Engl I Med 2001, 345:1359-1367.

27. Zivin JR, Gooley T, Zager RA, Ryan MJ: Hypocalcemia: a pervasive metabolic abnormality in the critically ill. Am J Kidney Dis 2001, 37:689-698.

28. Desai TK, Carlson RW, Geheb MA: Prevalence and clinical implications of hypocalcemia in acutely ill patients in a medical intensive care setting. Am J Med 1988, 84:209-214.

29. Burchard KW, Gann DS, Colliton J, Forster J: Ionized calcium, parathormone, and mortality in critically ill surgical patients. Ann Surg 1990, 212:543-549.

30. Aird WC: Endothelium as an organ system. Crit Care Med 2004, 32 S271-279.

31. Aird WC: Endothelial cell dynamics and complexity theory. Crit Care Med 2002, 30:5180-185

32. Aird WC: The role of the endothelium in severe sepsis and the multiple organ dysfunction syndrome. Blood 2003, 101:3765-3777.

33. Jeng L, Yamshchikov AV, Judd SE, Blumberg HM, Martin GS, Ziegler TR, Tangpricha V: Alterations in vitamin D status and anti-microbial peptide levels in patients in the intensive care unit with sepsis. J Trans/ Med 2009, 7:28

34. Pilz S, Dobnig H, Fischer JE, Wellnitz B, Seelhorst U, Boehm BO, März W: Low vitamin $D$ levels predict stroke in patients referred to coronary angiography. Stroke 2008, 39:2611-2613.

35. Pappa HM, Grand RJ, Gordon CM: Report on the vitamin D status of adult and pediatric patients with inflammatory bowel disease and its significance for bone health and disease. Inflamm Bowel Dis 2006, 12:1162-1174.
36. Arnson $Y$, Amital $H$, Shoenfeld $Y$ : Vitamin $D$ and autoimmunity: new aetiological and therapeutic considerations. Ann Rheum Dis 2007, 66:1137-1142.

37. Adorini L, Penna G: Control of autoimmune diseases by the vitamin D endocrine system. Nat Clin Pract Rheumatol 2008, 4:404-412.

38. Zold E, Szodoray P, Gaal J, Kappelmayer J, Csathy L, Gyimesi E, Zeher M, Szegedi G, Bodolay E: Vitamin D deficiency in undifferentiated connective tissue disease. Arthritis Res Ther 2008, 10:R123.

39. Sutherland ER, Goleva E, Jackson LP, Stevens AD, Leung DY: Vitamin D levels, lung function, and steroid response in adult asthma. Am J Respir Crit Care Med 2010, 181:699-704.

40. Hirani V, Primatesta P: Vitamin D concentrations among people aged 65 years and over living in private households and institutions in England: population survey. Age Ageing 2005, 34:485-491.

41. Krishnan A, Ochola J, Mundy J, Jones M, Kruger P, Duncan E, Venkatesh B: Acute fluid shifts influence the assessment of serum vitamin $D$ status in critically ill patients. Critical Care 2010, 14:R216.

42. Sambrook PN, Cameron ID, Cumming RG, Lord SR, Schwarz JM, Trube A March LM: Vitamin D deficiency is common in frail institutionalised older people in northern Sydney. Med J Aust 2002, 176:560.

43. Brock K, Wilkinson M, Cook R, Lee S, Bermingham M: Associations with vitamin D deficiency in "at risk" Australians. J Steroid Biochem Mol Biol 2004, 89-90:581-588.

44. González EA, Sachdeva A, Oliver DA, Martin KJ: Vitamin D insufficiency and deficiency in chronic kidney disease. A single center observational study. Am J Nephrol 2004, 24:503-510

45. Saab G, Young DO, Gincherman Y, Giles K, Norwood K, Coyne DW: Prevalence of vitamin $D$ deficiency and the safety and effectiveness of monthly ergocalciferol in hemodialysis patients. Nephron Clin Pract 2007, 105:c132-c138

46. Jean G, Terrat JC, Vanel T, Hurot JM, Lorriaux C, Mayor B, Chazot C: Daily oral 25-hydroxycholecalciferol supplementation for vitamin $D$ deficiency in haemodialysis patients: effects on mineral metabolism and bone markers. Nephrol Dial Transplant 2008, 23:3670-3676.

47. Pilz S, Tomaschitz A, Friedl A, Amrein K, Drechsler C, Ritz E, Boehm BO, Grammer TB, März W: Vitamin D status and mortality in chronic kidney disease. Nephrol Dial Transplant 2011, 26:3603-3609.

48. Pecovnik-Balon B, Jakopin E, Bevc S, Knehtl M, Gorenjak M: Vitamin D and mortality as a novel nontraditional risk factor for mortality in hemodialysis patients. Ther Apher Dial 2009, 13:268-272.

49. Drechsler C, Pilz S, Obermayer-Pietsch B, Verduijn M, Tomaschitz A, Krane V, Espe K, Dekker F, Brandenburg V, März W, Ritz E, Wanner C: Vitamin D deficiency is associated with sudden cardiac death, combined cardiovascular events, and mortality in haemodialysis patients. Eur Heart J 2010, 31:2253-2261.

50. Ravani P, Malberti F, Tripepi G, Pecchini P, Cutrupi S, Pizzini P, Mallamaci F, Zoccali C: Vitamin D levels and patient outcome in chronic kidney disease. Kidney Int 2009, 75:88-95.

51. Cheng S, Coyne D: Vitamin D and outcomes in chronic kidney disease. Curr Opin Nephrol Hypertens 2007, 16:77-82.

52. Mehrotra R, Kermah DA, Salusky IB, Wolf MS, Thadhani RI, Chiu YW, Martins D, Adler SG, Norris KC: Chronic kidney disease, hypovitaminosis D, and mortality in the United States. Kidney Int 2009, 76:977-983.

53. Jones G: Pharmacokinetics of vitamin D toxicity. Am J Clin Nutr 2008, 88:582S-586S.

54. Vieth R: Critique of the considerations for establishing the tolerable upper intake level for vitamin D: critical need for revision upwards. $J$ Nutr 2006, 136:1117-1122.

55. Amrein K, Sourij H, Wagner G, Holl A, Pieber TR, Smolle KH, Stojakovic T, Schnedl C, Dobnig H: Short-term effects of high-dose oral vitamin D3 in critically ill vitamin D deficient patients: a randomized, double-blind, placebo-controlled pilot study. Critical Care 2011, 15:R104.

56. Bjelakovic G, Gluud LL, Nikolova D, Whitfield K, Wetterslev J, Simonetti RG Bjelakovic M, Gluud C: Vitamin D supplementation for prevention of mortality in adults. Cochrane Database of Systematic Reviews 2011 , 7 : CD007470, DOI: 10.1002/14651858.CD007470.pub2.

\section{doi:10.1186/cc10585}

Cite this article as: Venkatram et al:: Vitamin D deficiency is associated with mortality in the medical intensive care unit. Critical Care 2011 15: R292. 